\title{
OS PRINCÍPIOS ORIENTADORES DO PLANEJAMENTO URBANO NO ESTADO AMBIENTAL E O DIREITO À CIDADE SUSTENTÁVEL
}

\author{
GUIDING PRINCIPLES OF URBAN PLANNING \\ IN THE ENVIRONMENTAL STATE AND THE \\ HUMAN RIGHT TO A SUSTAINABLE CITY
}

\author{
RICARDO LIBEL WALDMAN ${ }^{1}$ \\ AMANDA SCHÜLER BERTONI ${ }^{2}$ \\ FRANCESCO BOGONI ${ }^{3}$
}

\begin{abstract}
RESUMO: O artigo tem por objetivo apresentar princípios orientadores de planejamento e gestão urbana no sentido da implementação do direito à cidade sustentável. Neste sentido discute as relações entre o planejamento urbano e o contexto político mais amplo, em especial os modelos de Estado e a construção histórica dos direitos humanos.

PALAVRAS-CHAVE: Cidade; Sustentabilidade; Direitos Humanos; Planejamento Urbano.

ABSTRACT: The paper aims to present guiding principles of urban planning and governing towards the implementation of the right to a sustainable city. In this sense, it discusses the relationships between urban planning and the wider political context, especially State models and the historical construction of human rights.

KEYWORDS: City; Sustainability; Human Rights; Urban Planning.

SUMÁRIO: Introdução; 1 . O Contexto de Desenvolvimento do Planejamento Urbanístico; 2. O Estado Liberal e as Propostas Urbanas Modernas; 3. Os Períodos Pós-guerras e o Estado Social; 4. A Cidade Contemporânea e o Estado Ambiental; Conclusão; Referências Bibliográficas.
\end{abstract}

Artigo recebido em 21.05.2012. Pareceres emitidos em 05.09.2012, 03.02.2013 e 11.03.2013.

Artigo aceito para publicação em 10.03.2013.

${ }^{1}$ Doutor em Direito. Professor do Mestrado em Direitos Humanos e do Mestrado em Design do Centro Universitário Ritter dos Reis (UniRitter-RS). Professor da Faculdade de Direito da Pontifícia Universidade Católica do Rio Grande do Sul (PUCRS). Membro da Comissão de Especialistas em Direito Ambiental da IUCN. Advogado. ricardolibelwaldman@yahoo.com

${ }^{2}$ Mestre em Design no Centro Universitário Ritter dos Reis (UniRitter-RS). Arquiteta e Urbanista. Professora da Faculdade de Arquitetura e Urbanismo da Faculdade da Serra Gaúcha (FSG-RS). mandasbertoni@gmail.com

${ }^{3}$ Arquiteto e Urbanista. fra_bogoni@yahoo.it 
SUMMARY: Introduction; 1. Urban Planning Development Context; 2. Liberal State and Modern Urban Proposals; 3. Post-wars Periods and Welfare State; 4. Contemporary City and Environmental State; Conclusion; References.

\section{INTRODUÇÃO}

Este trabalho tem por objeto a apresentação de princípios orientadores de uma nova forma de planejamento e gestão do território urbano, voltada à realização do direito humano à cidade sustentável, ou seja, planejada e gerida no sentido da sustentabilidade. Transita, portanto, entre o urbanismo e o direito urbanístico, analisando o direito humano ao meio ambiente ecologicamente equilibrado, o qual, necessariamente, engloba o chamado meio ambiente artificial e, portanto, o direito à cidade sustentável.

Assim como o próprio urbanismo, o direito urbanístico, que surge pouco depois, tem a perspectiva de melhorar o ambiente urbano, num momento de intensa urbanização. Enquanto o urbanismo desenvolve modelos, o direito urbanístico estabelece as correspondentes regulamentações, tendo ambos por objetivo um controle funcional, sanitário e ambiental da estrutura física das cidades ${ }^{4}$.

Assim, este texto utilizará referenciais do urbanismo para buscar diretrizes para a legislação e gestão sobre as cidades, de maneira a possibilitar a construção de cidades sustentáveis.

Deste modo, na seção 2, será discutido o contexto em que planejamento e a gestão urbana vêm se desenvolvendo, conectando tais temas com a construção histórica dos direitos humanos e dos modelos de Estado a eles inerentes. Tal discussão será detalhada nas seções seguintes.

Na seção 3, será aprofundada a análise do Estado Liberal e dos direitos humanos ditos de primeira geração (ditos porque surgem primeiro), com a defesa intransigente da propriedade de um lado e a busca da racionalização dos espaços urbanos de outra.

A seção 4 descreve o Estado Social e os direitos ditos de segunda geração (à saúde, educação, previdência), com o surgimento de um planejamento urbano mais fortemente atuante na implementação de políticas públicas que asseguram tais direitos e, também, mais permeável às opiniões dos cidadãos.

A seção 5 discute o conceito de Estado Ambiental, cuja formatação se encontra ainda em fase de consolidação. Neste ponto, apresenta o direito à cidade sustentável (dito de terceira geração) e alguns princípios que devem dirigir um planejamento urbano orientado pela sustentabilidade no sentido amplo: econômico, ecológico e social. Também se discute o papel que a cidade pode ter no desenvolvimento sustentável mais amplo e as contradições a ele inerentes.

\footnotetext{
${ }^{4}$ MARTINS, Maria Lucia Refinetti. "São Paulo: além do plano diretor". In Estud. av. [online]. 2003, vol. $17, n^{\circ} 47$, p. 167-186. p. 7.
} 
O método utilizado foi o dialético, buscando analisar a construção histórica do direito a cidade sustentável e da correspondente forma de planejamento urbano, a partir da constatação dos conflitos inerentes aos modelos de organização social.

\section{O CONTEXTO DE DESENVOLVIMENTO DO PLANEJAMENTO URBANÍSTICO}

Para Doordan ${ }^{5}$, a arquitetura e o urbanismo são campos de atividade nos quais diferentes concepções do ambiente construído coexistem. Nesta perspectiva, os seus méritos respectivos devem ser debatidos pelos designers, administradores do território e o público em geral, eis que orientam atividades de grande importância política. Não se pode deixar de considerar que o sistema de planejamento urbano é consequência das transformações urbanas, especialmente do cenário que surge no século $X X$, com o crescimento das cidades e os conflitos por ela originados. Contudo, a base destas transformações inicia ao final do século XVIII acompanhada de mudanças políticas, sócias e demográficas.

As revoluções norte-americana e francesa introduziram a era da "política para as massas", transformando as fundações políticas, ao consolidar os direitos para o povo. As declarações de direitos, como o Bill of Rights na Inglaterra e a Declaração dos Direitos do Homem e Cidadão na França (1789), reconhecem os chamados direitos humanos de primeira geração (usa-se o termo geração apenas para referir sua anterioridade histórica), as liberdades públicas, que se relacionam basicamente com a não intervenção do Estado na vida dos indivíduos ${ }^{6}$. De acordo com Doordan ${ }^{7}$, a Revolução Industrial estabelece bases econômicas e materiais deste novo momento, desencadeando a capacidade produtiva ao combinar o conhecimento científico, o know-how tecnológico, e o espírito de iniciativa humana.

Portanto, o período moderno traz um desafio para os arquitetos e urbanistas enquanto designers do espaço urbano: conceber uma nova cidade, tanto no que se refere à sua integridade, como cada uma de suas partes.

Em uma grande medida, a história da arquitetura do século dezenove é a história dos esforços dos arquitetos e planejadores para chegar a um acordo com as possibilidades e problemas apresentados pela urbanização, mecanização, e secularização da vida moderna ${ }^{8}$.

Isto, porém, com limitações jurídicas importantes, como veremos, na medida em que o direito de propriedade é visto como absoluto, admitindo pouquíssimas limitações.

\footnotetext{
${ }^{5}$ DOORDAN, Dennis P. Twentieth-century Architecture. London: Calmann \& King Ltd, 2001.

${ }^{6}$ BOBBIO, Norberto. A Era dos Direitos. Rio de Janeiro: Campus, 1992.

${ }^{7}$ DOORDAN, Dennis P. Twentieth-century Architecture. London: Calmann \& King Ltd, 2001.

${ }^{8}$ DOORDAN, Dennis P. Twentieth-century Architecture. London: Calmann \& King Ltd, 2001. p. 77

- tradução livre.
} 
A situação alterou-se de maneira importante, em especial no segundo pós-guerra por parte do Estado $^{9}$, que incluem a saúde, a educação, o trabalho, a previdência e a moradia. Neste sentido, o planejamento urbano adquire nova e mais ampla função. Mas este novo contexto não eliminou o conflito entre a fascinação pelas tecnologias e inovações da Revolução Industrial e a rápida mudança do ambiente - conflito ainda atual.

As fábricas e as cidades em rápido crescimento transformaram a paisagem e, em muitas regiões, passaram a dominá-la, enquanto 'a terra verde e aprazível' recuou para segundo plano. Uma riqueza chegou para muitos; porém, aos olhos dos críticos, o preço pago foi alto demais ${ }^{10}$.

Atualmente se econtra em elaboração um modelo de gestão que forneça respostas mais adeq, na medida em que ao lado dos interesses dos proprietários, passam a ser reconhecidos os direitos e interesses dos trabalhadores, surgindo os direitos humanos de segunda geração, conectados a uma prestação uadas a tal conflito. Este virá a partir da construção de um Direito Internacional do Meio Ambiente, reconhecido pela primeira vez em um documento internacional na Declaração de Estocolmo, em 1972, feita pela Conferência das Nações Unidas sobre Meio Ambiente Humano ${ }^{11}$.

Sendo a cidade o meio ambiente onde vive a maior parte da população mundial, a busca da sustentabilidade passa necessariamente pelas cidades. É necessário, portanto, o reconhecimento de um direito à cidade sustentável. Neste sentido, a Agenda 21 brasileira, inclusive, como veremos procura definir a cidade sustentável ${ }^{12}$.

No Brasil, o direito à cidade está lastreado na Constituição de 1988, com sua política urbana que institui: "Art. 182. A política de desenvolvimento urbano, executada pelo Poder Público municipal, conforme diretrizes gerais fixadas em lei, tem por objetivo ordenar o pleno desenvolvimento das funções sociais da cidade e garantir o bem-estar de seus habitantes ${ }^{13 n}$.

$\mathrm{O}$ direito à cidade é um direito fundamental ou humano e de mesma hierarquia que os assegurados no art. $5^{\circ}$, em função do previsto no $\S 2^{\circ}$ do

\footnotetext{
${ }^{9}$ BOBBIO, Norberto. A Era dos Direitos. Rio de Janeiro: Campus, 1992.

${ }^{10}$ GIDDENS, Anthony. A Política da Mudança Climática. Trad. Vera Ribeiro. Rio de Janeiro: Zahar, 2010. p. 75.

${ }^{11}$ MAZZUOLLI, Valério de Oliveira; AYALA, Patrick de Araujo. Cooperação Internacional para a Preservação do Meio Ambiente: o direito brasileiro e a convenção de Aarhus. Disponível em http://seer.franca.unesp.br/index.php/estudosjuridicosunesp/article/view/332/329. Acesso em 06 maio 2012.

${ }^{12}$ FREIRE, Geovana Maria Cartaxo de Arruda. "Direito à cidade sustentável". Anais do XVII Congresso Nacional do CONPEDI 2008, realizado em Brasília-DF nos dias 20, 21 e 22 de novembro de 2008.

${ }^{13}$ FREIRE, Geovana Maria Cartaxo de Arruda. "Direito à cidade sustentável". Anais do XVII Congresso Nacional do CONPEDI 2008, realizado em Brasília-DF nos dias 20, 21 e 22 de novembro de 2008.
} 
mesmo dispositivo. O Estatuto da Cidade, por sua vez, garante o direito à cidade sustentável como "diretriz primeira da política urbana"14. Além disso:

\begin{abstract}
Questão das mais importantes de salientar é o fato de que a lei adota a sustentabilidade como um objetivo, utilizando conceito bastante amplo, expresso no artigo $2^{\circ}$, inciso VIII, para delimita-la:

"adoção de padrões de produção e consumo de bens e serviços e de expansão urbana compatíveis com os limites da sustentabilidade ambiental, social e econômica do Município e do território sob sua área de influência;" (grifo no original) ${ }^{15}$
\end{abstract}

Percebe-se, então, que o planejamento urbano chega ao atual estágio a partir no contexto da atribuição ao Estado de um número de tarefas cada vez maior, as quais são necessárias a satisfação de necessidades humanas e ambientais.

Nas próximas seções, será aprofundado o exame dos estágios mais relevantes deste desenvolvimento.

\title{
2. O ESTADO LIBERAL E AS PROPOSTAS URBANAS MODERNAS
}

Para Fernando Alves Correa ${ }^{16}$, o Direito Urbanístico no período do Estado Liberal, (que na Europa se deu no séc. XIX, e que no Brasil se estende até o séc. $X X)$ tem as seguintes características: i) a propriedade é considerada como direito absoluto, sagrado e inviolável; ii) há a liberdade para construir, com um mínimo de intervenção do poder público que por razões de saúde, segurança e ordem pública, considera as edificações isoladamente, sem considerar o todo do meio ambiente urbano; iii) submissão das limitações a liberdade de construir ao princípio da legalidade; iv) nos países mais industrializados, a existência de normas que visavam um mínimo de salubridade na moradia, entretanto, as normas são de cunho negativo, determinando abstenções, mas sem criar obrigações para o Estado, tais como criar habitações populares; v) utilização dos instrumentos tradicionais do direito urbanístico, a desapropriação por utilidade pública e os regulamentos de construção e por fim, vi) uma planificação mais ampla em termos de alinhamento das vias com o objetivo de facilitar o trânsito.

Neste contexto, a propriedade imóvel urbana é vista praticamente como mercadoria e o direito de construir, visto como acessório do direito de propriedade, não pode, portanto, ser considerado um bem alienável pelo

\footnotetext{
${ }^{14}$ ARAUJO, Suely Mara Vaz Guimarães de. O Estatuto da Cidade e a Questão Ambiental. Estudo. Abril 2003. Consultoria Legislativa da Câmara dos Deputados. Disponível em www2.camara.leg.br/documentos-e-pesquisa/.../pdf/304366.pdf. Acesso em 30 jan. 2013.

${ }^{15}$ ALFONSIN, Betânia. "O Estatuto da Cidade e a Construção de Cidades Sustentáveis, Justas e Democráticas". Direito e Democracia vol. 2, n 2, 2001: 309-317. p. 314

${ }^{16}$ CORREA, Fernando Alves. O Plano Urbanístico e o Princípio da Igualdade. Lisboa: Almedina, 1997.
} 
Estado como forma de compensar pela infra-estrutura que fornece ao particular nas zonas mais beneficiadas neste sentido ${ }^{17}$.

Os designers iniciam seu trabalho modificando a infra-estrutura de transporte regional com a inserção de novas estradas, para então criar uma distinção dos setores urbanos $^{18}$. O planejamento urbano se limita, basicamente, à organização das vias, de maneira coerente com o Estado Liberal, que procura minimizar a atuação do Poder Público.

A crise da cidade liberal nos países europeus, desde meados do século XIX, agravou-se em função de uma disputa política de profundas dimensões no papel dos instrumentos de regulação urbana e de políticas sociais para responder à exclusão social a que estavam relegados os trabalhadores na produção social das cidades. Já a industrialização ocorrida nas cidades brasileiras no final do século XIX e início do XX, sob o ponto de vista das transformações na estrutura urbana, adaptou-se às demandas do complexo agro-exportador, sem contudo demandar melhorias das condições gerais de produção entre as unidades e suas cadeias produtivas, assim como para a reprodução sócio-espacial da força de trabalho. ${ }^{19}$

Sendo assim, no âmbito do planejamento urbano, várias propostas surgiram para tentar estabelecer o modelo de cidade moderna. Para Amado ${ }^{20}$ algumas propostas modernas já apresentavam uma preocupação com 0 meio ambiente, por exemplo, a de Ebenezer Howard (1850-1928), propondo as "cidades jardins". Esta cidade combinaria as oportunidades culturais e educacionais da vida da cidade aos benefícios saudáveis e sustentáveis da vida no campo. Sua ideia era contrapor os modelos de periferia que estavam surgindo ao redor das grandes metrópoles.

Em contraponto a Howard, Daniel Burnham e Edward Bennet apresentam o movimento "cidade bonita", promovendo a ideia de novas cidades modernas grandiosas, inspiradas nos princípios das grandes cidades clássicas da antiguidade. Este modelo foi aplicado na modificação do plano da cidade de Chicago, Estados Unidos.

Já no Brasil:

A principal preocupação das reformas urbanísticas empreendidas nas cidades brasileiras na passagem do século XIX para o XX estava voltada para a otimização do funcionamento do complexo agro-exportador.

\footnotetext{
17 FERNANDES, Edésio. A Nova Ordem Jurídico-urbanística no Brasil. Disponível em www.conselhos.mg.gov.br/uploads/24/04.pdf. Acesso em 30 jan. 2013.

${ }^{18}$ DOORDAN, Dennis P. Twentieth-century Architecture. London: Calmann \& King Ltd, 2001. p. 5 - tradução livre.

${ }^{19}$ QUINTO JR, Luiz de Pinedo. "Nova legislação Urbana e os Velhos Fantasmas". Estud. av. [online]. 2003, vol. 17, no 47, p. 187-196. p. 188-189.

20 AMADO, Miguel Pires. Planeamento Urbano Sustentável. Casal de Cambra: Caleidoscópio: Edição e Artes Gráficas SA, 2005.
} 
As grandes transformações urbanas são realizadas procurando, entre outras coisas, evitar a interrupção do funcionamento dos portos brasileiros, como quando diversas epidemias tomaram conta das cidades litorâneas, principalmente a partir de $1860^{21}$.

Além disso, a Lei de Terras de 1850 tornou ilícita a posse como forma de aquisição da propriedade no País. A exclusividade do contrato de compra e venda para o acesso aos bens imóveis e o direito de propriedade tido como absoluto favoreceu a formação de um mercado imobiliário urbano ${ }^{22}$.

Consequência destes fatores (reformas no direito urbanístico e absolutização do direito de propriedade) foi uma cisão do território das cidades brasileiras em zonas legais e ilegais, uma situação que até hoje o Estatuto da Cidade procura solucionar ${ }^{23}$.

Pelo ano de 1925, Le Corbusier lança Urbanisme, oferecendo uma visão de uma Paris modificada, em moldes similares a Burnham e Bennet. Para Le Corbusier, a simplicidade geométrica das formas arquitetônicas estaria em harmonia com as demandas de precisão e padronização consideradas o "coração" do que significava a maneira moderna de produção. "Luz e ar, o grito de batalha dos reformuladores urbanos desde a metade do século dezenove, preenche o espaço da nova cidade e tudo é governado por uma simplicidade lúcida e geométrica ${ }^{24}$."

Em geral, as estratégias projetuais que surgiram no começo do século, dependem do contexto determinado pelo local e as legislações nacionais, os recursos financeiros e a localização disponível dos sítios construtivos. Na Holanda em 1902 há a criação de uma nova legislação com o propósito de estabelecer um novo programa de habitação. O "The Housing Act" necessitou de uma preparação dos planos diretores municipais no sentido de: limitar o crescimento urbano; criar códigos para construção; estender o poder de desapropriação do estado; e, estabelecer fundos e procedimentos para financiar novas construções ${ }^{25}$.

$\mathrm{Na}$ Alemanha, o uso de projetos residenciais de larga escala provou ser outro dilema. Políticas locais e condições econômicas foram críticas para

\footnotetext{
${ }^{21}$ QUINTO JR, Luiz de Pinedo. “Nova Legislação Urbana e os Velhos Fantasmas". In Estud. av. [online]. 2003, vol. 17, no 47, p. 187-196. p.189.

${ }^{22}$ ALFONSIN, Betânia. O Significado do Estatuto da Cidade para os Processos de Regularização Fundiária no Brasil. Disponível em http://www.sedur.ba.gov.br/pdf/versao.final.pdf. Acesso em 25 jan. 2012.

${ }^{23}$ ALFONSIN, Betânia. O Significado do Estatuto da Cidade para os Processos de Regularização Fundiária no Brasil. Disponível em http://www.sedur.ba.gov.br/pdf/versao.final.pdf. Acesso em 25 jan. 2012.

${ }^{24}$ LE CORBUSIER apud DOORDAN, Dennis P. Twentieth-century Architecture. London: Calmann \& King Ltd, 2001. p. 12 - tradução livre.

${ }^{25}$ DOORDAN, Dennis P. Twentieth-century Architecture. London: Calmann \& King Ltd, 2001. p. 15 - tradução livre.
} 
definir os parâmetros das decisões projetuais. No caso dos Estados Unidos, ao contrário da Europa o governo preferiu reformar a legislação para impor controles em construções privadas ao invés de investir em novas moradias $^{26}$.

\section{OS PERÍODOS PÓS-GUERRAS E O ESTADO SOCIAL}

O período correspondente a Segunda Guerra Mundial, para Doordan ${ }^{27}$ significou um período de grandes mudanças no século $X X$, uma vez que envolveu uma grande mobilidade de pessoas, indústrias, serviços e recursos, inclusive no que se refere à arquitetura e o urbanismo. No pós-guerra surgiu a necessidade pela reconstrução, renovação e criação de novas cidades. A guerra deu origem a inovações, criando a necessidade por construções e metodologias projetuais em um ritmo acelerado, tendo sido utilizados, portanto, materiais pré-fabricados assim como novas tecnologias.

Os direitos humanos também foram bastante afetados na sua compreensão e conteúdo:

(...) com a positivação dos direitos fundamentais sociais econômicos e culturais, objetos até mesmo de um pacto internacional específico (Pacto Internacional dos Direitos Econômicos, Sociais e Culturais de 1966) se pretendeu em última análise, a compensação das gritantes desigualdades econômicas acarretadas ao longo da revolução industrial (embora esta, à evidência, não tenha instaurado a pobreza no mundo), buscando a concretização da idéia de justiça material, por meio de uma liberdade e igualdade não meramente formais, bem como pela proteção da liberdade pessoal em relação ao exercício do poder social e econômico, que resultou na afirmação das liberdades sociais, como é o caso da liberdade de associação sindical e do direito de greve ${ }^{28}$.

O planejamento urbano recebeu significância ao representar a organização política e social, na configuração das capitais, sendo um exemplo a cidade de Brasília. Tendo para Doordan ${ }^{29}$ o significado, portanto, de um agente de transformação, auxiliando na criação de uma identidade nacional, assim como a estimulação do desenvolvimento de áreas como o transporte, comunicação e geração de energia. A capital brasileira, tanto em seu projeto urbano criado por Lúcio Costa, como nas criações arquitetônicas de Oscar Niemeyer, tornou-se símbolo do progresso brasileiro. Entretanto, o planejamento urbano sofisticou-se no Brasil em um modelo tecnocrático,

${ }^{26}$ DOORDAN, Dennis P. Twentieth-century Architecture. London: Calmann \& King Ltd, 2001. p. 18 - tradução livre.

${ }_{27}$ DOORDAN, Dennis P. Twentieth-century Architecture. London: Calmann \& King Ltd, 2001.

${ }^{28}$ SARLET, Ingo W. "Algumas Considerações em Torno do Conteúdo, Eficácia e Efetividade do Direito à Saúde na Constituição de 1988". Revista Eletrônica sobre Reforma do Estado. № 11 , set./out./nov. 2007. Salvador. p. 7.

${ }^{29}$ DOORDAN, Dennis P. Twentieth-century Architecture. London: Calmann \& King Ltd, 2001. 
autoritário, que refletiu no benefício para a especulação urbana e na exclusão das camadas mais pobres ${ }^{30}$.

O séc. XX na Europa, especialmente depois da $2^{\mathrm{a}}$ Guerra Mundial, viu o surgimento de um novo direito urbanístico, mais ativo e mais participativo. Este novo direito urbanístico (objetivo) está relacionado com uma nova geração dos direitos humanos (subjetivos), os chamados direitos sociais e que incluem o trabalho, a moradia, a saúde, entre outros. Estes direitos, cada vez mais, precisam ser satisfeitos na cidade. A diferença crucial entre estes direitos e aqueles de primeira geração é que os mesmos são direitos a uma prestação positiva de parte do Estado $^{31}$ e o direito urbanístico é instrumento fundamental para a realização destas prestações, exigindo, por exemplo, doação de imóveis para a instalação de equipamentos e vias públicas, praças etc, como faz a Lei 6.766/79.

As principais características são: i) uma mudança de postura da Administração Pública, que deixa de preocupar-se, apenas, em regular a atuação dos privados, evitando danos à saúde e ao funcionamento das vias públicas, e passa a atuar na criação de infra-estrutura pública, construção de habitações populares entre outras; ii) construção de um "urbanismo de concertação", no qual as várias esferas do governo colaboram no planejamento urbano, que passa a ter um papel central no direito urbanístico, sendo que seus fins se ampliam para além dos limites mencionados na seção anterior, atingindo todas as formas de uso, ocupação e transformação do solo, por exemplo, com o uso da técnica do zoneamento; iii) a funcionalização da propriedade, que deixa de ser um direito absoluto; iv) utilização de novos instrumentos, tais como obrigatoriedade de cedência de terrenos à Administração, realização de obras de urbanização pelo particular; a operações em parceria entre a Administração e proprietários, entre outros; v) busca da melhoria da qualidade de vida, inclusive com cuidados com o meio ambiente e, por fim, o surgimento de normas gerais sobre ocupação e uso do solo ${ }^{32}$.

No Brasil, onde as cidades foram planejadas de forma excludente ${ }^{33}$, pode-se dizer que este cenário somente se consolida com o Estatuto da Cidade, Lei 10.257/01. Esta Lei, regulamentando a Política Urbana prevista na Constituição de 1988, de fato estabelece instrumentos para a correta funcionalização da propriedade urbana e busca melhoria da qualidade de vida da população como um todo.

\footnotetext{
30 FERNANDES, Edésio. A Nova Ordem Jurídico-urbanística no Brasil. Disponível em www.conselhos.mg.gov.br/uploads/24/04.pdf. Acesso em 30 jan. 2013.

${ }^{31}$ SARLET, Ingo W. "Algumas Considerações em torno do Conteúdo, Eficácia e Efetividade do Direito à Saúde na Constituição de 1988". Revista Eletrônica sobre Reforma do Estado. № 11, set./out./nov. 2007. Salvador.

${ }^{32}$ CORREA, Fernando Alves. O Plano Urbanístico e o Princípio da Igualdade. Lisboa: Almedina, 1997.

${ }^{33}$ SANTIN, Janaína Rigo. A Gestão Democrática Municipal no Estatuto da Cidade e a Teoria do Discurso Habermasiana. Disponível em ojs.c3sl.ufpr.br/ojs2/index.php/direito/article/download/ 5177/3893. Acesso em 30 jan. 2013.
} 


\section{A CIDADE CONTEMPORÂNEA E O ESTADO AMBIENTAL}

$\mathrm{Na}$ cidade contemporânea, os urbanistas lidam com o aumento da população, redução dos recursos, degradação ambiental e conflitos sociais. De acordo com a Avaliação dos Ecossistemas do Milênio de $2005^{34}$ :

nos últimos 50 anos, os humanos modificaram os ecossistemas mais rápida e extensivamente que em qualquer período semelhante na história da humanidade", e [...] isso resultou em "uma substancial e em grande parte irreversível perda da diversidade da vida na Terra.

A década de 1960 trouxe grandes mudanças no campo da arquitetura e urbanismo. Dentre elas, a criação do desenvolvimento suburbano, ou seja, bairros afastados do centro que se desenvolvem quase que independentes do mesmo para o que foi determinante a influência dos automóveis.

Uma das características mais salientes da organização do espaço urbano contemporâneo é, ao nosso ver, a sua descontinuidade, resultado manifesto do pensamento que está na sua origem, pensamento esse que permitiu pôr hipóteses e aceitar realidades que hoje começam a apresentar-se a nós como condenáveis e negativos ${ }^{35}$.

Os subúrbios urbanos, assim como a cidade contemporânea, de forma geral apresentam dificuldades. Para Tavora ${ }^{36}$, esta cidade é consequência das mudanças que surgem no período moderno e apresenta uma dimensão de problemas inéditos. "Ela constitui assim mais uma soma de espaços do que um todo estruturado, em que se misturam e confundem funções, em que a desordem é soberana ${ }^{37}$."

A urbanização crescente e a degradação ambiental que a acompanha acaba por fragilizar os tecidos sociais, especialmente, mas não só, em países pobres, fazendo com que surjam movimentos migratórios. Tais movimentos geram conflitos dentro dos Estados e entre os Estados, especialmente quando os imigrantes, muitas vezes verdadeiros refugiados, não são desejados ${ }^{38}$.

Assim, também, a problemática ambiental é de primeira importância e de caráter internacional, como bem exemplifica o aquecimento global:

\footnotetext{
${ }^{34}$ STOODART, Hannah. (Ed) A Pocketguide to Sustainable Development Governance. $1^{\text {st }}$. edition for comments by $15^{\text {th }}$ July 2011. Stakeholder Forum Secretariat: s. Ed., s.d. p.7 - tradução livre.

35 TÁVORA, Fernando. Da Organização do Espaço. Porto: Faculdade de Arquitectura da Universidade do Porto, 2006. p. 34

36 TÁVORA, Fernando. Da Organização do Espaço. Porto: Faculdade de Arquitectura da Universidade do Porto, 2006.

37 TÁVORA, Fernando. Da Organização do Espaço. Porto: Faculdade de Arquitectura da Universidade do Porto, 2006. p. 35

${ }^{38}$ HURREL, Andrew. "The state". In: Political Theory and the Ecological Challenge. DOBSON, A. \& ECKERSLEY, R. (eds). New York: Cambridge University Press, 2006.
} 
O Painel Intergovernamental sobre as Mudanças Climáticas [sigla em inglês IPCC] descobriu que as emissões globais de CO2 cresceram 70\% entre 1970 e 2004. Isso apesar do arrebatador consenso científico de que níveis crescentes de $\mathrm{CO} 2$ na atmosfera causados por atividades humanas representam uma ameaça séria ao bem estar humano. Este lapso de tempo também corresponde ao período durante o qual a comunidade global veio a entender o impacto do homem no meio ambiente melhor do que nunca e tem desenvolvido um sistema em contínua expansão de governança global planejado para atender a estes problemas ${ }^{39}$.

Estas questões se manifestam principalmente na década de setenta com a "explosão" da questão ambiental e a tomada de consciência dos limites do desenvolvimento econômico fundamentado nos limites dos recursos. Em âmbito internacional sucedem-se uma série de apontamentos e agendas (sobretudo conferências da Organização das Nações Unidas e Comunidade Européia) com o objetivo de definir em detalhes o novo modelo de desenvolvimento e de como aplicá-lo, entre outros através das políticas setoriais. Convém referir que esta mudança de rumo não ocorre sem conflitos e que as necessidades e interesses econômicos exercem um papel que não pode ser desconsiderado ${ }^{40}$.

Surge, então, a busca pela sustentabilidade. De acordo com Bosselmann ${ }^{41}$, o termo sustentabilidade ainda não apresenta uma conceituação consensual, mas aqui utiliza-se a ideia, conforme este mesmo autor, de uma integração entre as atividades humanas, seu crescimento econômico, o desenvolvimento da sociedade e a manutenção da integridade dos ecossistemas. Esta, entendida como preservação do funcionamento dos ecossistemas existentes põe limite ao desenvolvimento econômico e social.

Um exemplo de como lidar com estas realidades, no âmbito do urbanismo, é representado pela cidade de Curitiba. Lerner apud Doordan ${ }^{42}$ enquanto atua na prefeitura da cidade inclusive como prefeito, estabelece uma estratégia para lidar com o rápido crescimento urbano. Esta estratégia tem como enfoque os problemas sociais e ambientais, criando um sistema de transporte em massa, o aumento das áreas verdes ao redor da cidade, programas para a reciclagem de resíduos, assim como trabalhos para melhorar a vida dos habitantes das regiões das favelas. "A experiência de Curitiba foi eleita como um modelo de design 'verde' e um poderoso lembrete do potencial do design

\footnotetext{
${ }^{39}$ STOODART, Hannah. (Ed) A Pocketguide to Sustainable Development Governance. $1^{\text {st }}$. edition for comments by $15^{\text {th }}$ July 2011. Stakeholder Forum Secretariat: s. Ed., s.d. p.7 - tradução livre.

40 TARLOCK, A. Dan. “Contested Landscapes and Local Voice”. 3 Wash. U. J.L. \& Pol'y 5132000. p. 513-537. FOSTER, Sheila R. "From Harlem to Havana: Sustainable Urban Development". 16 Tul. Envtl. L.J. 783 2002-2003. p. 783-805.

41 BOSSELMANN, K., ENGEL, R. \& TAYLOR, P. Governance for Sustainability: issues, challenges, successes. Gland: IUCN, 2008.

42 DOORDAN, Dennis P. Twentieth-century Architecture. London: Calmann \& King Ltd, 2001.
} 
para sustentar tanto o ambiente natural como o construído ${ }^{43}$." Aliás, a cidade pode ser um locus importante de desenvolvimento de políticas de redução de emissão de carbono, especialmente com a regulamentação da construção civil, buscando a disseminação de prédios verdes ${ }^{44}$.

Portanto, um caminho a ser adotado para um melhor desenvolvimento do território urbano estaria na cidade sustentável. A necessidade por um urbanismo "sustentável" surge nos últimos decênios do século XX, em conexão com as reflexões a respeito de um "desenvolvimento sustentável", considerando-se que a ideia de sustentabilidade sempre esteve implícita na história da arquitetura e urbanismo, representando o ideal de um projeto que atende a todos os princípios básicos do "problema" arquitetônico a que atende. Nas palavras de Sant'Ellia apud Lemos ${ }^{45}$, a "arquitetura é o esforço de harmonizar o ambiente e o homem, tornando o mundo das coisas uma projeção direta do mundo do espírito".

Assim, passa-se a falar de um direito humano ao meio ambiente ecologicamente equilibrado, direito humano de terceira geração, caracterizado por possuir sujeitos ativos e passivos indeterminados. Diferentemente das liberdades públicas e dos direito sociais, os direitos de terceira geração ou dimensão não são direitos de determinadas pessoas isoladamente, mas de todos ao mesmo tempo, fundados que estão na solidariedade humana ${ }^{46}$.

É possível individualizar princípios e conceitos de um urbanismo sustentável que são geralmente reconhecidos no cenário internacional. São eles: cidade sustentável, cidade ecológica, cidade de proximidade, cidade reumanizada, cidade autogerida e cidade como elemento da sociedade multi-local.

\section{1 o Princípio: Cidade sustentável}

Define-se desenvolvimento sustentável, um modelo de desenvolvimento que "satisfaz a necessidade do presente sem comprometer a capacidade das gerações futuras de satisfazer os seus próprios ${ }^{47}$." Esta definição adotada através do Relatório sobre Meio Ambiente e Desenvolvimento das Nações Unidas (conhecido como Relatório Brundtland) declara o princípio ético fundamental de que cada indivíduo (de hoje ou do futuro) possui os mesmos direitos para satisfazer suas próprias necessidades. A definição do Relatório Brundtland não fala propriamente das habitações, mas refere-se principalmente ao bem-estar das pessoas, incluindo a qualidade ambiental. Esta definição

\footnotetext{
${ }^{43}$ DOORDAN, Dennis P. Twentieth-century Architecture. London: Calmann \& King Ltd, 2001. p. 253 - tradução livre.

${ }^{44}$ SUSSMAN, Edna. "Reshaping municipal and county laws to foster green building, energy efficiency, and renewable energy". 16 N.Y.U. Envtl. L.J. 1 2008. p. 1-43.

${ }^{45}$ LEMOS, Carlos. O que é Arquitetura. São Paulo: Livraria Brasiliense Editora S.A., 1980.

${ }^{46}$ FENSTERSEIFER, Tiago. Estado Socioambiental de Direito e o Princípio da Solidariedade como seu Marco Jurídico-constitucional. Disponível em: http://www.egov.ufsc.br/portal/sites/ default/files/anexos/26947-26949-1-PB.htm. Acesso em 12 fev. 2012.

47 UNITED NATIONS. Report of the World Commission on Environment and Development: Our Common Future. New York: United Nations, 1987. p. 54 - tradução livre.
} 
vem ampliada na Agenda 21 - adotada na Conferência das Nações Unidas no Rio de Janeiro em 1992 - segundo a qual "o objetivo geral que se segue consiste em melhorar a qualidade social, econômica e ambiental das habitações humanas, e as condições de vida e trabalho de todos ${ }^{48}$."

Deste modo, definem-se as três dimensões do desenvolvimento sustentável: social, econômico e ambiental, que, devem ser consideradas contemporaneamente para o desenvolvimento dos ambientes. Assim, introduz-se outro conceito chave que tem origem nas teorias do sistema ecológico segundo as quais "tudo é conectado a tudo", modificando assim a compreensão de sustentabilidade de um produto final para um processo dinâmico em transformação ${ }^{49}$.

Uma caracterização posterior do conceito é a da Carta de Aalborg ${ }^{50}$ na ocasião da primeira Conferência Européia das Cidades Sustentáveis. Tal documento, em sua declaração de princípios afirma que "a sustentabilidade não representa um estado nem uma visão imutável, mas sim, um processo local, criativo" e que "cada cidade possui sua especificidade e para tanto acontece que cada encontra sua própria forma de sustentabilidade ${ }^{51}$."

De forma mais específica em relação ao planejamento urbano, o Relatório da ONU sobre ambientes declara que "não existe um modelo único de planejamento que possa ser aplicado em cada parte do mundo. Porém é possível generalizar ideias e conceitos de planejamento, os quais possam ser utilizados independentes dos fatores locais ${ }^{52 ، .}$. Enuncia-se assim, outro elemento chave para a definição das cidades sustentáveis: a sua especificidade, tornando impossível a adoção de um modelo universal, assim requisitando uma formulação específica para cada caso devido ao caráter local, reconduzindo a formulação do modelo baseado nos critérios da realidade aos quais pertencem.

Deste modo, do ponto de vista da repartição das competências em nível constitucional, por exemplo, é relevante que os governos locais recebam competências em matéria ambiental $^{53}$, como acontece no Brasil, no art. 23 da Constituição Federal. Isto permite uma maior adequação das exigências da sustentabilidade com a realidade concreta de cada cidade.

\footnotetext{
${ }^{48}$ UNITED NATIONS CONFERENCE ON ENVIRONMENT AND DEVELOPMENT (UNCED). Agenda 21. Rio Declaration on Environment and Development. Statement of principles for the sustainable management of forests. New York: United Nations. 1993.

${ }_{49}$ ADHYA, A.; PLOWRIGHT, P.; STEVENS, J. "Defining Sustainable Urbanism: towards a responsive urban design". In: Proceedings of the Conference on Sustainability and the Built Environment. Riyadh: King Saud University, 2010. p. 2.

${ }^{50}$ CONFERENZA EUROPEA SULLE CITTA SOSTENIBILI (CECS). Carta delle Città Europee per uno sviluppo durevole e sostenibile. Aalborg: Commissione Europea. 1994.

${ }^{51}$ CONFERENZA EUROPEA SULLE CITTA SOSTENIBILI (CECS). Carta delle Città Europee per uno sviluppo durevole e sostenibile. Aalborg: Commissione Europea. 1994. p. 2 - tradução livre.

52 UNITED NATIONS HUMAN SETTLEMENT PROGRAM (UN-HABITAT). Planning Sustainable Cities: global report on human settlements. London: Sterling. 2009. p. 78 - tradução livre.

53 TARLOCK, A. Dan. "Contested Landscapes and Local Voice". 3 Wash. U. J.L. \& Pol'y 513 2000. p. 513-537.
} 
Mas o aspecto econômico da sustentabilidade não pode ser desconsiderado e ele pode gerar tanto oportunidades quanto obstáculos. Oportunidades porque podem, por exemplo, gerar recursos para a revitalização de uma área degradada, obstáculos porque podem, por exemplo, trazer pressões para minimizar gastos ou utilizar mais recursos naturais que, na verdade, seriam necessários para a manutenção da qualidade de vida de populações em situação de risco e da integridade ecológica ${ }^{54}$.

\subsection{O Recurso: cidade ecológica}

Frente à tendência global da urbanização em constante aumento e ao crescimento da população urbana, a posição amplamente partilhada e adotada pelos governos é de agir estrategicamente procurando "reduzir a pressão dos centros urbanos maiores e privilegiar centros urbanos menores, os integrando com seus espaços rurais circundantes ${ }^{55}$." De acordo com Véron ${ }^{56}$, a preferência pelo desenvolvimento de centros urbanos de dimensões controladas é seguidamente retomada nas agendas internacionais ${ }^{57}$ (Agenda 21, Habitat II) debatendo-se os limites da economia de escala, segundo as quais são garantidas melhores condições nos centros mais que nos grandes aglomerados urbanos. A Agenda 21 motiva o desenvolvimento das cidades intermediárias pelas suas maiores possibilidades de "criar oportunidades de emprego para a população da zona rural [...] e desenvolver atividades econômicas de escala local, em particular a produção de alimentos, para suportar a produção e o consumo local ${ }^{58 ،}$.

O conceito de interdependência deve basear-se no equilíbrio dos fluxos entre a cidade e o campo, e impedir a cidade de apenas desfrutar dos recursos das áreas circundantes. Portanto, a sustentabilidade ou não de uma cidade deve ser considerada em relação ao território do qual pertence, assumindo que "desenvolvimento rural e urbano são interdependentes ${ }^{59}$." Dessa forma, o conceito de cidade sustentável aparece como parte de um sistema ecológico, não podendo ser considerada isoladamente. Isto explica a atenção à dimensão urbana, que deve ser proporcional à disponibilidade e

\footnotetext{
${ }^{54}$ TARLOCK, A. Dan. "Contested Landscapes and Local Voice”. 3 Wash. U. J.L. \& Pol'y 5132000. p. 513-537. FOSTER, Sheila R. "From Harlem to Havana: Sustainable Urban Development". 16 Tul. Envtl. L.J. 783 2002-2003. p. 783-805.

${ }_{55}$ UNITED NATIONS. Report of the World Commission on Environment and Development: Our Common Future. New York: United Nations, 1987. p. 12 - tradução livre.

${ }^{56}$ VÉRON, Jaques. L'urbanizzazione del Mondo. Bologna: II Mulino. 2008.

57 UNITED NATION CONFERENCE ON HUMAN SETTLEMENTS (HABITAT II). The Habitat Agenda: goals and principles, commitments and the global plan of action. New York: United Nations. 1996.

${ }_{58}$ UNITED NATIONS CONFERENCE ON ENVIRONMENT AND DEVELOPMENT (UNCED). Agenda 21. Rio Declaration on Environment and Development. Statement of principles for the sustainable management of forests. New York: United Nations. 1993.

${ }^{59}$ UNITED NATION CONFERENCE ON HUMAN SETTLEMENTS (HABITAT II). The Habitat Agenda: goals and principles, commitments and the global plan of action. New York: United Nations. 1996.
} 
à capacidade de regeneração dos recursos presentes no território. Aqui fica bastante evidente a ideia de sustentabilidade presente em Bosselmann, segundo a qual a integridade ecológica é um limite para a satisfação das pretensões humanas ${ }^{60}$.

Aceitando-se esta visão torna-se, porém, importante que as vantagens oferecidas pelo ambiente urbano contribuam com o desenvolvimento das rurais. Obtém-se isto através da extensão dos bens e serviços produzidos no ambiente urbano - infra-estrutura, serviços públicos e oportunidades de emprego - ao ambiente rural "com o objetivo de aumentar a atração, e estabelecer uma rede integrada de ambientes e minimizar a migração ruralurbana $^{61}$." Dessa forma, vem justificado e aprovado o processo de urbanização sustentável, enquanto "fenômeno positivo, e condição para melhorar o acesso a serviços e oportunidades econômicas e sociais ${ }^{62}$." É, portanto, reafirmada a supremacia da cidade no processo de desenvolvimento sustentável do território, superando a visão desenvolvida da ecologia urbana, segundo a qual, a cidade é antiecológica.

\subsection{Formas: cidade compacta}

Existe um senso comum segundo o qual é possível definir as características formais gerais na estruturação da cidade sustentável. Na realidade, a vontade de definir a "cidade sustentável" do ponto de vista formal leva à atenção o que Adhya, Plowright e Stevens ${ }^{63}$ definem como "um paradoxo do design urbano."

Segundo os autores, de fato, tradicionalmente era de lugar comum concentrar-se em conceitos abstratos formalizados a partir de princípios da compreensão morfológica modernista da cidade, até a noção pluralista pós-moderna de ambiente urbano. Porém, ao aceitar uma visão processual de sustentabilidade, o planejamento urbano deve concentrar-se no objeto enquanto um complexo sistema de relações, muito mais do que no projeto em si como formalização de regras gerais.

Ao aceitar esta concessão que não individualiza soluções sustentáveis em regras formais, se reconhecem as características que no estado atual das dinâmicas urbanas, permitem aproximar-se de uma situação mais sustentável dos sistemas habitacionais. A definição de "cidade compacta" como modelo sustentável (sobretudo nos países ocidentais), que devem possuir características espaciais de "maior densidade [populacional], porém alturas reduzidas

60 BOSSELMANN, K.; ENGEL, R. \& TAYLOR, P. Governance for Sustainability: issues, challenges, successes. Gland: IUCN, 2008.

${ }^{61}$ UNITED NATION CONFERENCE ON HUMAN SETTLEMENTS (HABITAT II). The Habitat Agenda: goals and principles, commitments and the global plan of action. New York: United Nations. 1996.

${ }^{62}$ UNITED NATIONS HUMAN SETTLEMENT PROGRAM (UN-HABITAT). Planning Sustainable Cities: global report on human settlements. London: Sterling. 2009. p. 78 - tradução livre.

63 ADHYA, A., PLOWRIGHT, P., STEVENS, J. "Defining Sustainable Urbanism: towards a responsive urban design". In: Proceedings of the Conference on Sustainability and the Built Environment. Riyadh: King Saud University, 2010. 
[ou seja, prédios com menos pavimentos]; mistura de usos [comercial e residencial na mesma zona]; ser baseada no transporte público; integração espacial; sistema de espaços abertos definidos e seguros; limites urbanos para prevenir a difusão ${ }^{64}$."

Esta visão apresenta-se como uma resposta a "cidade difusa", fenômeno que pressupõe a extensão das zonas perimetrais, a multiplicação dos deslocamentos e dos problemas de transporte, que demonstra a sua natureza insustentável por uma série de consequências: emissão de gás provocando o efeito estufa, multiplicação das formas de poluição, descontextualização, desperdício de solos, etc. Além disso, a redução das distâncias possibilitada pelo uso do automóvel restituiu a separação rígida das funções, trazendo o desaparecimento dos quarteirões compactos de funções mistas.

O "novo urbanismo" reconhecendo esta crítica promove o retorno à organização tradicional dos quarteirões urbanos como estratégia para contrastar o desenvolvimento urbano "com manchas de óleo" (sprawling). Assim, é fundamental a mistura de funções, permitindo reduzir a necessidade de deslocamento. A intenção é, também, induzir a uma mudança de comportamento, no momento em que "estratégias que enfatizam o uso misto e desenvolvimento denso, levarão mais facilmente as pessoas a viver mais próximas aos locais de trabalho e aos serviços necessários à vida cotidiana ${ }^{65}$." Verifica-se, também, a conveniência de aproximar dos centros urbanos igualmente as atividades que frequentemente vêm localizadas na periferia, como as indústrias - no caso as de pequeno e médio porte compatíveis com o ambiente urbano. A sua inclusão, além de limitar a necessidade por deslocamento, contribuem para aumentar as ofertas de trabalho ${ }^{66}$.

Vale destacar que nos Estados Unidos há uma tendência divergente identificando mega-regiões ${ }^{67}$ de um lado e de outro com uma integração entre homem e natureza ${ }^{68}$. A tendência das mega-regiões teria por vantagem, por exemplo, considerar as bacias-hidrográficas, já que os limites urbanos não coincidem, necessariamente, com os naturais. A integração homem e natureza, por sua vez, está relacionada com a manutenção dos modos de vida das comunidades que vivem com os recursos naturais que the são próximos ao invés de desviá-los para centros urbanos mais ou menos distantes deixando a natureza o mais possível intocada.

\footnotetext{
${ }^{64}$ UNITED NATIONS HUMAN SETTLEMENT PROGRAM (UN-HABITAT). Planning Sustainable Cities: global report on human settlements. London: Sterling. 2009. p. 79 - tradução livre.

${ }^{65}$ EUROPEAN COMMISSION. Green: paper on the urban environment. Brussels: European Commission. 1990. p.40 - tradução livre.

${ }^{66}$ EUROPEAN COMMISSION. Green: paper on the urban environment. Brussels: European Commission. 1990.

${ }^{67}$ ROSS, C.L. et al. Measuring Regional Transportation Sustainability: An Exploration. 42/43 Urb. Law. 67 2010-2011. p. 67-89.

${ }^{68}$ TARLOCK, A. Dan. "Contested Landscapes and Local Voice". 3 Wash. U. J.L. \& Pol'y 5132000. p. 513-537.
} 


\subsection{Uso: cidade reumanizada}

A cidade sustentável deve procurar satisfazer as necessidades de todas as categorias (social, de idade e riqueza) das populações. Porque "a desigualdade da riqueza é motivo do comportamento insustentável ${ }^{69}$." Assim, é necessário priorizar as faixas com menos possibilidades econômicas e a integração social. As populações menos favorecidas são as que mais contribuem (diretamente) aos problemas ambientais, sendo também as que menos têm recursos para resolver tais problemas.

O Relatório Brundtland, analisando as condições urbanas em nível global, distinguia os problemas em dois níveis de gravidade: os países ocidentais e os países em desenvolvimento, sendo os segundos com os problemas mais graves: "habitações ilegais com serviços primitivos, superpopulação e ambientes não salutares ${ }^{70}$." As estratégias propostas seriam o aumento das oportunidades de trabalho, a criação e a melhoria dos serviços básicos, assim como a melhoria da qualidade dos espaços urbanos. A Declaração de Vancouver afirma que "o planejamento de sucesso é inclusivo, para os pobres, reconhece a diversidade e promove a igualdade", o que reforça outro elemento importante da cidade sustentável, a sua flexibilidade em relação aos modelos de gestão e organização espacial e social. Estes não estão baseadas em regras rígidas e pré-definidas, acolhendo, ao invés, soluções "guiadas pelo objetivo e prioridades de todos os grupos da cidade ${ }^{71}$."

\subsection{Gestão: governança local}

Como foi visto, os sistemas de gestão urbana servem como estratégias para o desenvolvimento sustentável, revendo a manutenção e o melhoramento das infra-estruturas e serviços, as modalidades de gestão dos solos, a luta contra a pobreza urbana, etc. Progressivamente a inflexão foi intitulada de "governança urbana" como "sistema de relações entre instituições, organizações e indivíduos" pondo em consideração as dimensões políticas do desenvolvimento urbano ${ }^{72}$. Importante destacar que:

Primeiro, governança não é governo. Governança como um conceito reconhece que o poder existe dentro e fora das autoridades e instituições do governo. Em muitas formulações, governança inclui governo, setor privado e sociedade civil. Segundo, governança enfatiza "processo". Ela reconhece que as decisões são tomadas através de relacionamentos

\footnotetext{
${ }^{69}$ CONFERENZA EUROPEA SULLE CITTA SOSTENIBILI (CECS). Carta delle Città Europee per uno Sviluppo Durevole e Sostenibile. Aalborg: Commissione Europea. 1994. p. 3 - tradução livre.

${ }^{70}$ UNITED NATIONS. Report of the World Commission on Environment and Development: Our Common Future. New York: United Nations, 1987. p. 32 - tradução livre.

${ }^{71}$ WORLD PLANNERS CONGRESS (WPC). Vancouver Declaration. Vancouver: World Planners Congress. 2006 - tradução livre.

${ }^{72}$ Ascher apud VÉRON, Jaques. L'urbanizzazione del Mondo. Bologna: II Mulino. 2008. p. 107 tradução livre.
} 
complexos entre muitos atores com diferentes prioridades. (tradução nossa, nota omitida. ${ }^{73}$

Na Carta de Aalborg ${ }^{74}$ lê-se que a administração local reparte com os cidadãos as responsabilidades de resolução dos problemas tanto ambientais como de outros níveis, em busca de um bem-estar da população e a preservação natural. Esta afirmação individualiza dois elementos da governança urbana: o papel fundamental da cidade no projeto e gestão dos elementos urbanos compatíveis com um modelo sustentável e o papel das nações para definir as políticas e os planos dos quais vem enunciados os princípios inspiradores e os objetivos. Estes vêm reunidos no "princípio de subsidiar", segundo o qual "enquanto os governos nacionais têm o papel de organizar programas e políticas de desenvolvimento urbano, a subvenção reconhece a necessidade de descentralizar, pondo no governo local o papel principal e reforçando a organização de base comunitária ${ }^{75}$."

$\mathrm{Na}$ verdade, o modelo de governança sustentável requer inovação frente aos modelos atuais.

\subsection{Inovação: cidade como elemento da sociedade multi-local}

A cidade pode ser um locus de inovação no sentido da sustentabilidade, reconhecendo as dimensões globais da crise ambiental. Neste sentido, pode-se falar na cidade como elemento de uma sociedade multi-local que engloba três aspectos fundamentais, de acordo com Manzini ${ }^{76}:$ 1) Localidades cosmopolitas: estas localidades caracterizam-se por, reconhecendo e valorizando suas especificidades históricas e culturais, integrar-se e tirar proveito da globalização sócio-econômica e cultural. Exemplo deste tipo de práticas são as regiões vinícolas que procuram ter suas produções identificadas e reconhecidas por suas qualidades no mercado internacional, 2) Comunidades criativas: grupos de pessoas que se organiza para fazer coisas de formas diferentes, buscando uma qualidade de vida e 3) Redes colaborativas: as pessoas participam de projetos conjuntos de elaboração de conhecimento, projetos e produtos em que o usuário é fornecedor do produto/serviço.

$\mathrm{Na}$ sociedade multi-local, as localidades cosmopolitas e as comunidades criativas levam para as redes colaborativas a diversidade de problemas e soluções construídas na vida cotidiana. Nesse sentido, a globalização é um

\footnotetext{
${ }^{73}$ United Nations Human Settlements Programme, UN-HABITAT. The Global Campaign on Urban Governance. Disponível em http://ww2.unhabitat.org/campaigns/governance/docs_pubs.asp Acesso em 27 jan. 2013.

${ }^{74}$ CONFERENZA EUROPEA SULLE CITTA SOSTENIBILI (CECS). Carta delle Città Europee per uno Sviluppo Durevole e Sostenibile. Aalborg: Commissione Europea. 1994.

${ }^{75}$ WORLD PLANNERS CONGRESS (WPC). Vancouver Declaration. Vancouver: World Planners Congress. 2006.

76 MANZINI, Ezio. Design Research for Sustainable Social Innovation. Disponível em http://www.sustainable-everyday.net/manzini/ Acesso em 07 set. 2011.
} 
sistema de localidades que, ciente de suas identidades, estão integradas nas questões globais.

O empoderamento de indivíduos e comunidades, combinada com uma forte ênfase em formas descentralizadas de organização política (...) facilitam a sustentabilidade de diversas formas: aproximando consumo e produção; fortalecendo a democracia local e focando a oposição pública na seriedade dos problemas ambientais existentes; e crescendo na medida em que os grupos e comunidades locais possuem conhecimento especial de formas sustentáveis de desenvolvimento e proporcionam as organizações sociais dentro das quais este conhecimento pode ser implementado efetivamente. ${ }^{77}$

A cidade da sustentabilidade precisa ser um local onde soluções são construídas e a partir do qual são compartilhadas. As tecnologias e estilos de vida que permitem consumo menor de recursos naturais podem ser gerados nas cidades e compartilhados em rede de modo que elas possam ser reelaborados de acordo com a visão de mundo e ecossistemas de cada contexto.

De outro lado, a sociedade multi-local permite o reconhecimento de que, ao lado de identidades parciais existem problemas ambientais e éticos globais que precisam ser enfrentados, também, com base em uma nova ética e, quem sabe, um novo direito de cunho internacional ${ }^{78}$.

Neste contexto, é possível falar em duas tendências: a internacionalização das cidades, que através de associações passam a ser atores na política internacional e de outro a localização do desenvolvimento sustentável com o trabalho dos governos e comunidades locais no sentido de soluções para os problemas ambientais, sociais e econômicos ${ }^{79}$. Estas duas tendências precisam ser interligadas em rede para que as contradições por elas geradas não acabem gerando problemas como a supressão de instâncias relevantes no nível nacional, a influência desmedida do capital privado frente aos poderes locais muitas vezes falidos, a ausência de compartilhamento de gestão de cidades que se localizam, como já referido, numa mesma bacia hidrográfica, entre outros.

\subsection{Estado Ambiental}

Sendo assim, o Estado Ambiental é um modelo que ainda está em gestação, mas que procura garantir um papel central ao meio ambiente na tomada de decisão sobre políticas públicas, "apontando mecanismos para um controle ambiental favorável à garantia de dignidade humana e equilíbrio

\footnotetext{
${ }^{77}$ HURREL, Andrew. "The state". In: Political Theory and the Ecological Challenge. DOBSON, A. \& ECKERSLEY, R. (eds). New York: Cambridge University Press, 2006. p. 172 - tradução livre.

78 BOSSELMANN, K., ENGEL, R. \& TAYLOR, P. Governance for Sustainability: issues, challenges, successes. Gland: IUCN, 2008.

${ }^{79}$ PORRAS, Ileana M. "The City and International Law: in pursuit of sustainable development". 36 Fordham Urb. L.J. 537 2009. p. 537-601.
} 
dos ecossistemas, bem como a gestão de riscos." ${ }^{80}$ Suas características são: i) a compreensão sistêmica do meio ambiente, entendido em seus aspectos natural, urbano, cultural e do trabalho; ii) o compromisso ético de não empobrecer a Terra e a sua biodiversidade, almejando, com isso, manter as opções das futuras gerações e garantir a própria sobrevivência das espécies e de seu habitat; iii) a atualização do direito de propriedade, visando a sustentabilidade; iv) a opção por processos decisórios abertos, transparentes, bem informados e democráticos, estruturados em torno do devido processo ambiental, v) a preocupação com a implementação e a previsão, já na própria constituição de certos tipos de diretos e deveres relacionados à eficácia do Direito Ambiental e de seus instrumentos, visando a evitar que a norma maior, não só ela, assuma uma feição retórica, vi) o reconhecimento de que a soberania é limitada pelo caráter global da crise ambiental ${ }^{81}$ e vii) favorecimento da formulação de soluções locais construidas em rede com base em valores globais ${ }^{82}$.

Vale reforçar que o Estado Ambiental não é pós-social, no sentido que as questões dos direitos sociais ainda se colocam $^{83}$ e estão fortemente relacionadas com a sustentabilidade. O próprio relatório Brundtland refere que o desenvolvimento sustentável passa por sociedades mais justas e que os países desenvolvidos deveriam colaborar com os países em desenvolvimento na erradicação da pobreza, visualizando uma relação entre pobreza, desigualdade e degradação ambiental ${ }^{84}$.

Por fim, o Estado Ambiental, na sua busca pelo desenvolvimento sustentável, deve lidar, entre outras, com duas tensões que tocam as cidades de maneira importante: por um lado a tensão entre objetivos econômicos e objetivos ambientais por outro lado entre e as esferas locais e globais ${ }^{85}$. Isto porque os interesses econômicos historicamente têm papel importante na tomada de decisões e porque ainda é necessária a construção de uma estrutura política internacional que, ao mesmo tempo, ofereça oportunidade de efetiva participação para as estruturas locais e reforce o necessário contexto global de discussão sobre o desenvolvimento sustentável.

\footnotetext{
${ }^{80}$ LEITE, J.R.M., PILATI, L.C. \& JAMUNDÁ, W. "Estado de Direito Ambiental no Brasil" In: Desafios do Direito Ambiental no Séc. XXI: estudos em homenagem a Paulo Affonso Leme Machado, KISHI, Sandra Akemi Shimada et al. (orgs.). São Paulo: Malheiros, 2005. p. 611-634. p. 632.

${ }^{81}$ HURREL, Andrew. "The state". In: Political Theory and the Ecological Challenge. DOBSON, A. \& ECKERSLEY, R. (eds). New York: Cambridge University Press, 2006.

82 MANZINI, Ezio. Design Research for Sustainable Social Innovation. Disponível em http://www.sustainable-everyday.net/manzini/ Acesso em 07 set. 2011.

${ }^{83}$ FENSTERSEIFER, Tiago. Estado Socioambiental de Direito e o Princípio da Solidariedade como seu Marco Jurídico-constitucional. Disponível em: http://www.egov.ufsc.br/portal/sites/ default/files/anexos/26947-26949-1-PB.htm. Acesso em 12 fev. 2012.

${ }^{84}$ UNITED NATIONS. Report of the World Commission on Environment and Development: Our Common Future. New York: United Nations, 1987.

${ }^{85}$ PORRAS, Ileana M. "The City and International Law: in pursuit of sustainable development". 36 Fordham Urb. L.J. 537 2009. p. 537-601.
} 


\section{CONCLUSÃO}

O direito a cidade sustentável é resultado de uma construção histórica que remonta ao reconhecimento dos direitos humanos de primeira geração, os quais exigiam um afastamento do Estado da vida privada, e ao Estado Liberal, quando o urbanismo se constitui como elemento neste contexto. Das contradições do Estado Liberal surge o Estado Social, com os direitos de segunda geração, exigindo prestações do Estado, as quais são implementadas em parte, através do planejamento urbano. Mas este Estado Social com sua crescente urbanização, além de muitos outros fatores, gerou grande impacto no meio ambiente e na cidade tornou-se necessário procurar formas de desenvolvimento sustentável, o qual permite a todos, hoje e no futuro, a satisfazerem suas necessidades.

A partir daí é possível falar em um direito à cidade sustentável o qual é garantido, no Brasil, através do Estatuto da Cidade. Mas a cidade sustentável se insere em um novo Estado, o Estado Ambiental, em que a integridade ecológica é um limite para as atividades humanas.

O Estado Ambiental é um Estado em formação, ainda não consolidado, no qual podem se dar as melhores condições para o planejamento e gestão urbanos sustentáveis, os quais devem ser, necessariamente, socialmente justos. Isto porque somente com o compromisso com o meio ambiente aliado a instrumentos eficazes e processos decisórios abertos, bem informados e democráticos em uma cidade humanizada, que trata todos como iguais, se poderá planejar e gerir para a sustentabilidade das cidades. Portanto, a educação ambiental, o planejamento urbano participativo e a colaboração através das sociedades multi-locais são condições necessárias para este novo Estado.

Neste sentido, os princípios e conceitos orientadores do planejamento e da gestão urbano: a) cidade sustentável: é aquela que permite a manutenção da qualidade de vida das presentes e futuras gerações, sendo que a forma de implementação de tal modelo depende do contexto de cada cidade ou país, mas é possível formular alguns princípios gerais; b) cidade ecológica: a cidade deve estar integrada com os ecossistemas nas quais está inserida, não devendo significar uma ruptura com os mesmos; c) cidade compacta: deve haver a centralização de recursos em áreas densas de modo a exigir menos deslocamentos; d) cidade reumanizada: a justiça social, com a redução da pobreza e seus efeitos ambientais, deve ser um objetivo da gestão urbana; e) governança local: os poderes públicos municipais devem receber competências que permitam sua atuação na busca da sustentabilidade, do mesmo modo, a sociedade civil deve participar a todo momento da formação das políticas públicas e f) sociedade multi-local: os Municípios podem e devem construir redes internacionais nas quais soluções podem ser compartilhadas, problemas discutidos e oportunidades de crescimento abertas, as formas de alcançar a sustentabilidade devem ser desenvolvidas de acordo com cada 
realidade local, beneficiando-se das redes colaborativas características de nossa época. Assim, até mesmo as soluções participativas podem ser facilitadas.

Entretanto, e finalizando, há uma série de obstáculos a serem superados neste processo, em especial a questão econômica e a dificuldade de encontrar o caminho político necessário para que se avance democraticamente no sentido de uma sociedade sustentável.

A problemática econômica, com a pressão que exerce para o uso intensivo dos recursos aliada a necessidade de empregos e impostos de muitas cidades gera uma tensão importante.

Além disso, o Direito Internacional tem visto a soberania ser relativizada pela globalização, pelos direitos humanos e pela crise ambiental. Novos caminhos precisam ser encontrados, mas as necessidades específicas de cada país e as diferenças culturais, dentre outros problemas dificultam a formação de um modelo ambiental satisfatório.

\section{REFERÊNCIAS BIBLIOGRÁFICAS}

ADHYA, A.; PLOWRIGHT, P.; STEVENS, J. "Defining Sustainable Urbanism: towards a responsive urban design". In: Proceedings of the Conference on Sustainability and the Built Environment. Riyadh: King Saud University, 2010.

ALFONSIN, Betânia. "O Estatuto da Cidade e a Construção de Cidades Sustentáveis, Justas e Democráticas". Direito e Democracia, vol. 2, n 2, 2001: 309-317.

ALFONSIN, Betânia. O Significado do Estatuto da Cidade para os Processos de Regularização Fundiária no Brasil Disponível em http://www.sedur.ba.gov.br/pdf/ versao.final.pdf. Acesso em 25 jan. 2012.

AMADO, Miguel Pires. Planeamento Urbano Sustentável. Casal de Cambra: Caleidoscópio: Edição e Artes Gráficas SA, 2005.

ARAUJO, Suely Mara Vaz Guimarães de. O Estatuto da Cidade e a Questão Ambiental. Estudo. Abril 2003. Consultoria Legislativa da Câmara dos Deputados. Disponível em www2.camara.leg.br/documentos-e-pesquisa/.../pdf/304366.pdf. Acesso em 30 jan. 2013.

BOBBIO, Norberto. A Era dos Direitos. Rio de Janeiro: Campus, 1992.

BOSSELMANN, K.; ENGEL, R. \& TAYLOR, P. Governance for Sustainability: issues, challenges, successes. Gland: IUCN, 2008.

CONFERENZA EUROPEA SULLE CITTA SOSTENIBILI (CECS). Carta delle Città Europee per uno Sviluppo Durevole e Sostenibile. Aalborg: Commissione Europea. 1994.

CORREA, Fernando Alves. O Plano Urbanístico e o Princípio da Igualdade. Lisboa: Almedina, 1997.

DOORDAN, Dennis P. Twentieth-century Architecture. London: Calmann \& King Ltd, 2001. EUROPEAN COMMISSION. Green: paper on the urban environment. Brussels: European Commission. 1990.

FENSTERSEIFER, Tiago. Estado Socioambiental de Direito e o Princípio da Solidariedade como seu Marco Jurídico-constitucional. Disponível em: http://www.egov.ufsc.br/portal/ sites/default/files/anexos/26947-26949-1-PB.htm. Acesso em 12 fev. de 2012. 
FERNANDES, Edésio. A Nova Ordem Jurídico-urbanística no Brasil. Disponível em www.conselhos.mg.gov.br/uploads/24/04.pdf. Acesso em 30 jan. 2013.

FREIRE, Geovana Maria Cartaxo de Arruda. "Direito à Cidade Sustentável". Anais do XVII Congresso Nacional do CONPEDI 2008, realizado em Brasília-DF nos dias 20, 21 e 22 de novembro de 2008.

GIDDENS, Anthony. A Política da Mudança Climática. Trad. Vera Ribeiro. Rio de Janeiro: Zahar, 2010. p. 75.

HURREL, Andrew. "The state". In: Political Theory and the Ecological Challenge. DOBSON, A. \& ECKERSLEY, R. (eds). New York: Cambridge University Press, 2006.

LEITE, J.R.M.; PILATI, L.C. \& JAMUNDÁ, W. "Estado de Direito Ambiental no Brasil" In: Desafios do Direito Ambiental no Séc. XXI: Estudos em homenagem a Paulo Affonso Leme Machado, KISHI, Sandra Akemi Shimada et al. (orgs.). São Paulo: Malheiros, 2005. p. 611-634.

LEMOS, Carlos. O que é Arquitetura. São Paulo: Livraria Brasiliense Editora S.A., 1980. MANZINI, Ezio. Design Research for Sustainable Social Innovation. Disponível em http://www.sustainable-everyday.net/manzini/ Acesso em 07 set. 2011.

MARTINS, Maria Lucia Refinetti. "São Paulo: além do plano diretor". In Estud. av. [online]. 2003, vol. 17, n 47, p. 167-186.

MAZZUOLLI, Valério de Oliveira; AYALA, Patrick de Araujo. Cooperação Internacional para a Preservação do Meio Ambiente: o direito brasileiro e a convenção de Aarhus. Disponível em http://seer.franca.unesp.br/index.php/estudosjuridicosunesp/article/view/ 332/329. Acesso em 06 maio 2012.

PORRAS, Ileana M. "The City and International Law: in pursuit of sustainable development". 36 Fordham Urb. L.J. 537 2009. p. 537-601.

QUINTO JR, Luiz de Pinedo. "Nova Legislação Urbana e os Velhos Fantasmas". Estud. av. [online]. 2003, vol. 17, n 47, p. 187-196.

ROSS, C. L. et al. Measuring Regional Transportation Sustainability: An Exploration. 42/43 Urb. Law. 67 2010-2011. p. 67-89.

SANTIN, Janaína Rigo. A Gestão Democrática Municipal no Estatuto da Cidade e a Teoria do Discurso Habermasiana. Disponível em ojs.c3sl.ufpr.br/ojs2/index.php/ direito/article/download/5177/3893. Acesso em 30 jan. 2013.

SARLET, Ingo W. "Algumas Considerações em Torno do Conteúdo, Eficácia e Efetividade do Direito à Saúde na Constituição de 1988". Revista Eletrônica sobre reforma do Estado. № 11, set./out./nov. 2007. Salvador.

STOODART, Hannah.(Ed) A Pocketguide to Sustainable Development Governance. $1^{\text {st }}$. edition for comments by $15^{\text {th }}$ July 2011 . Stakeholder Forum Secretariat: s. Ed., s.d.

SUSSMAN, Edna. "Reshaping Municipal and County Laws to Foster Green Building, Energy Efficiency, and Renewable Energy". 16 N.Y.U. Envtl. L.J. 1 2008. p. 1-43.

TARLOCK, A. Dan. "Contested Landscapes and Local Voice”. 3 Wash. U. J.L. \& Pol'y 513 2000. p. 513-537. FOSTER, Sheila R. "From Harlem to Havana: Sustainable Urban Development”. 16 Tul. Envtl. L.J. 783 2002-2003. p. 783-805.

TÁVORA, Fernando. Da Organização do Espaço. Porto: Faculdade de Arquitectura da Universidade do Porto, 2006. 
UNITED NATIONS. Report of the World Commission on Environment and Development: Our Common Future. New York: United Nations, 1987.

UNITED NATIONS CONFERENCE ON ENVIRONMENT AND DEVELOPMENT (UNCED). Agenda 21. Rio Declaration on Environment and Development. Statement of principles for the sustainable management of forests. New York: United Nations. 1993.

UNITED NATIONS HUMAN SETTLEMENT PROGRAM (UN-HABITAT). Planning Sustainable Cities: global report on human settlements. London: Sterling. 2009.

UNITED NATIONS HUMAN SETTLEMENTS PROGRAMME, UN-HABITAT. The Global Campaign on Urban Governance. Disponível em http://ww2.unhabitat.org/ campaigns/governance/docs_pubs.asp Acesso em 27 jan. 2013.

UNITED NATION CONFERENCE ON HUMAN SETTLEMENTS (HABITAT II). The Habitat Agenda: goals and principles, commitments and the global plan of action. New York: United Nations. 1996.

VÉRON, Jaques. L'urbanizzazione del Mondo. Bologna: II Mulino. 2008.

WORLD PLANNERS CONGRESS (WPC). Vancouver Declaration. Vancouver: World Planners Congress. 2006. 